\title{
EFECTO DE LA TASA DE COMPRESIÓN EN LA MORFOLOGÍA DE GRIETAS DE DEBOBINADO PARA CHAPAS DE Eucalyptus nitens
}

\author{
NOSE BAR PRESSURE EFFECT IN THE LATHE CHECK \\ MORPHOLOGY TO Eucalyptus nitens VENEERS
}

\author{
Andrés Acevedo ${ }^{1 \star}$, Cecilia Bustos ${ }^{1}$, Jean Pierre Lasserre², William Gacitúa ${ }^{1}$
}

\begin{abstract}
RESUMEN
El objetivo de este estudio fue evaluar el efecto de tres tasas de compresión (TC) en la morfología de grietas de debobinado en chapas de Eucalyptus nitens para la fabricación de tableros contrachapados. Chapas secas se obtuvieron desde un proceso de debobinado, con $1.8 \mathrm{~mm}$ de espesor a tres tasas de compresión $\mathrm{TC} 1=0.5 \%$; TC2 $=3.5 \%$ y TC $3=5 \%$, las que se consiguieron ajustando la barra de presión y el cuchillo del torno debobinador marca Cremona de una planta de contrachapados del sur de Chile. Se obtuvieron probetas en forma aleatoria de los tres tipos de chapas procesadas. Fotografías fueron tomadas en el espesor de las chapas para el posterior procesamiento de imágenes. En el análisis morfológico de las grietas se evalúo: largo, área y frecuencia en las probetas para las tres tasas de compresión estudiadas. El análisis morfológico de imágenes mostró que existe una disminución del largo y profundidad de las grietas, así como también del área de grietas, cuando se aumenta la tasa de compresión. Diferencias significativas fueron halladas entre los niveles $0.5 \%$ y $5 \%$ de tasa de compresión. Esto implica que al aumentar la tasa de compresión, a través de un ajuste que involucra una menor distancia entre la barra de presión y el cuchillo debobinador, se obtienen chapas de mejor calidad, más rígidas y con una reducción del agrietamiento superficial en el tablero final.
\end{abstract}

Palabras claves: Grietas de debobinado, tasa de compresión, chapas, debobinado, Eucalyptus nitens.

\begin{abstract}
The objective of this study was to evaluate the effect of three nose bar pressure (TC) in the morphology of the lathe checks in Eucalyptus nitens veneers for the manufacture of plywood. Dried veneers were obtained from a peeling process, $1.8 \mathrm{~mm}$ thick three nose bar pressure TC1 $=0.5 \%$, TC2andTC $3=3.5 \%=5 \%$, which were obtained by adjusting the pressure bar and peeling knife of Cremona the in a plywood plant in southern Chile. Samples were obtained randomly from the three types of veneers processed. Photographs were taken in the veneer thickness for subsequent image processing. In the morphological analysis of the cracks was evaluated: length, area and frequency in the samples for the three nose bar pressure studied. Morphological analysis of images showed that a decrease in the length and depth of the lathe check, as well as the area, when the nose bar pressure increases. Significant differences were found between $0.5 \%$ and $5 \%$ levels of nose bar pressure. This implies that increasing the nose bar pressure, through a setting that involves a smaller distance between the pressure bar and peeling knife, you get better quality veneers, more rigid and with a reduction of surface cracking in the final plywood.
\end{abstract}

Keywords: Lathe checks, nose bar pressure, veneers, peeling process, Eucalyptus nitens.

\footnotetext{
${ }^{1}$ Departamento de Ingeniería en Maderas, Universidad del Bío-Bío. Concepción. Chile.

${ }^{2}$ Forestal Mininco S.A., Concepción. Chile. jean.lasserre@forestal.cmpc.cl

Autor para correspondencia: ^andaceve@alumnos.ubiobio.cl

Recibido: 24.11.2011 Aceptado: 26.06.2012.
} 


\section{INTRODUCCIÓN}

El Eucalyptus nitens (Deane \& Maiden) Maidenes una especie forestal de rápido crecimiento, que está siendo plantada de manera creciente en Chile y destinada principalmente a la producción de celulosa. Sin embargo, debido a los permanentes cambios que presenta el mercado de la madera y la necesidad de obtener mayores retornos económicos de los cultivos forestales, resulta aconsejable desarrollar otros productos provenientes de estas plantaciones, como trozas para madera aserrada y chapas para otorgarle mayor valor agregado (Muñoz et al. 2005).

El debobinado es un proceso a través del cual se obtiene una chapa continua de madera mediante un corte tangencial a los anillos de crecimiento. La troza es montada entre dos fijadores centrales y ésta gira en contra de un cuchillo fijo del mismo largo de la troza. En este proceso, el corte y la separación de las fibras de madera dificultan la obtención de chapas. La separación de la madera, durante el corte en tornos de debobinado, causa variaciones de espesor, rugosidad de la superficie, chapa ondulada y grietas de debobinado entre otras (Marchal et al. 2009).

En el proceso de debobinado participan el cuchillo debobinador, que es el que realiza el corte en la madera, y la barra de presión que es la que mantiene la chapa presionada sobre el cuchillo para dar estabilidad al corte y dar también el espesor constante a la chapa (Marchal et al. 2009). En la obtención de la chapa, la superficie donde actúa la barra de presión se llama cara apretada y la superficie donde se produce el corte por el cuchillo se llama cara suelta; en esta última se producen las grietas de debobinado, las cuales también se asocian a las fuerzas de corte. Cuando el cuchillo corta la madera éste produce una ruptura extensible de la fibra ocasionada por la punta de la herramienta de corte (Figura 1). Este fenómeno ha sido estudiado por varios investigadores (De Vallance et al. 2007, Denaud et al. 2007, Marchal et al. 2009, Palubicki et al. 2009), debido a que es una de las principales variables en el debobinado, que afectan la calidad de la chapas y la calidad del tablero (Marchal et al. 2009).

Existen dos características principales que describen las grietas de debobinado, estas son, la profundidad en el espesor y los intervalos o frecuencia de las grietas a lo largo de la chapa (Palubicki et al. 2009, Marchal et al. 2009, Denaud et al. 2007). Estas características dependen de la combinación de velocidades de rotación y vibración del torno, la fuerza que ejerce la barra de presión en el proceso y la calidad del filo del cuchillo de debobinado, además del tipo de materia prima y la calidad del macerado de las trozas.

Distintas metodologías se han desarrollado para medir estos parámetros a escala de laboratorio; por ejemplo, una metodología en línea para detectar las grietas de debobinado y su frecuencia mediante mediciones acústicas y de vibración del torno, ajustando la presión de la barra presión y concluyendo que las grietas de debobinado son proclives a aparecer cuando se varía la de presión de la barra (Denaud et al. 2007). 


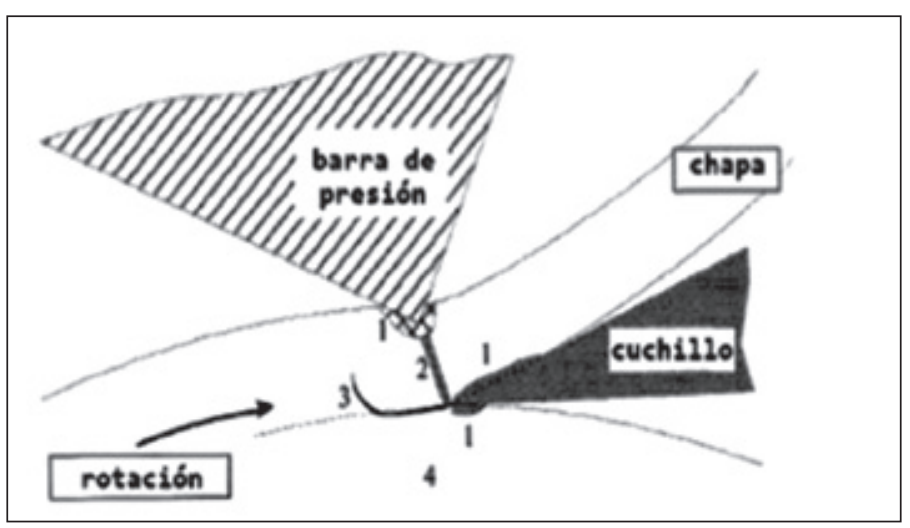

Figura 1. Esquema de obtención de una chapa de madera (Marchal et al. 2009).

1-Trituración y roce ejercida por el cuchillo y la barra de presión 2-Plano principal de cizalladura

3-Ruptura extensible ejercida por la punta del cuchillo

4-Desplazamiento elástico lejos del cuchillo y la barra de presión

Métodos de análisis de imágenes han sido desarrollados, para la medición de grietas de debobinado en la chapa. Instalando una cámara a un lado de la chapa, lo que permite visualizar la geometría de las grietas en la sección transversal (Figura 2). Las grietas se abren al doblar la chapa en un rodillo de un diámetro específico, de tal manera que se garantice una buena visibilidad de las grietas. El método es automático y ofrece información valiosa sobre la morfología de las grietas de debobinado, es decir, distancias entre éstas, largo, frecuencia y profundidad (Palubicki et al. 2009).

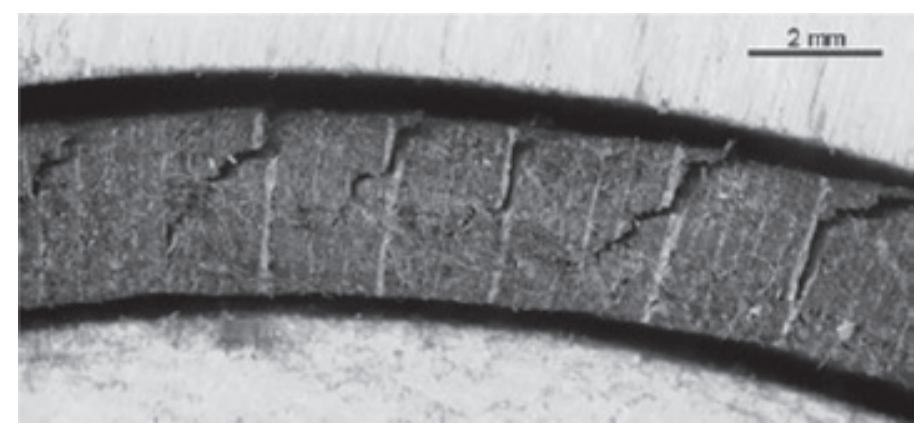

Figura 2. Vista lateral de chapas observada bajo microscopio (Palubicki et al. 2009).

Por otra parte, la temperatura de macerado y la tasa de compresión (TC) son parámetros importantes que deben ser medidos y controlados en la producción de chapas, ya que condiciona la calidad superficial de éstas, además de la resistencia mecánica de los tableros posteriormente fabricados (Devlieger et al. 1986).

El objetivo de esta investigación fue evaluar el efecto de la variable "tasa de compresión" en la morfología de las grietas de debobinado. La tasa de compresión se define como la diferencia entre el espesor de la chapa $\left(\mathrm{E}_{\mathrm{v}}\right)$ y la distancia real entre la barra de presión y el cuchillo debobinador $(\mathrm{Ch})$, siendo común denominador el espesor de la chapa $\left(\mathrm{E}_{\mathrm{v}}\right)$; ecuación 1, figura 3. 


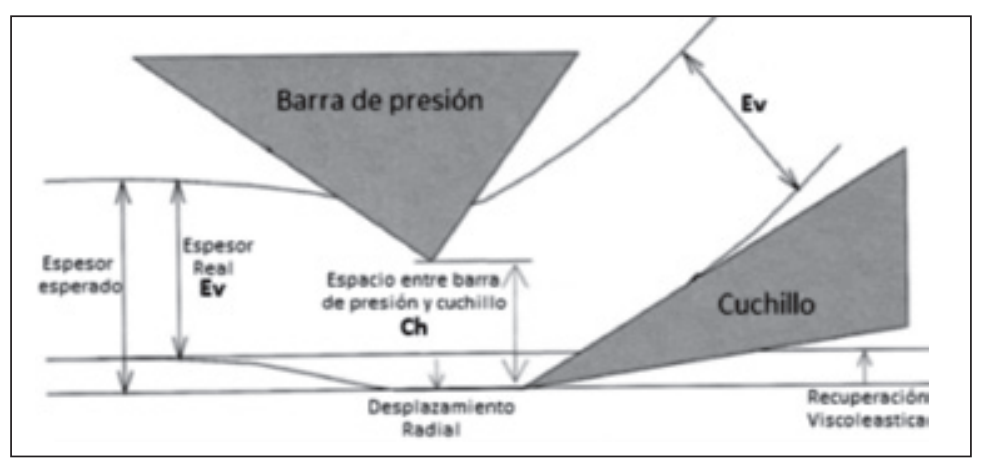

Figura 3. Consecuencia del desplazamiento radial de la madera en el espesor de chapa a nivel de la punta debido a las fuerzas de corte (Marchal et al. 2009).

\section{MATERIALES Y MÉTODO}

\section{Materia Prima:}

La materia prima, consistió en nueve trozas de Eucalyptus nitens de 13 años de edad, obtenidas de árboles de la familia codificada como 2820 con procedencia Toorongo y raza South CentVic, estas trozas provienen de un predio de Forestal Mininco S.A. en la zona de Mulchén, ubicado en la región del Bío-Bío, Chile. El suelo del predio es de tipo arcilloso y el diámetro menor de las trozas debobinadas fue de $28 \mathrm{~cm}$ (diámetro punta fina sin corteza), todas las trozas utilizadas provienen de la primera sección de los árboles entre la base hasta los $3 \mathrm{~m}$. El dimensionado de la troza para el proceso de debobinado fue de $2.73 \mathrm{~m}$ donde se utilizaron 3 trozas para cada tasa de compresión posteriormente calculadas.

\section{Tasa de Compresión:}

La tasa de compresión porcentual utilizada en el torno debobinador, fue calculada usando la ecuación 1.

$$
T C=\frac{E_{V}-C_{h}}{E_{V}} \times 100 \%
$$

Donde:

TC = Tasa de Compresión (\%)

$\mathrm{E}_{\mathrm{V}}=$ Espesor de la chapa $(\mathrm{mm})$

$\mathrm{Ch}=$ Distancia entre cuchillo y barra de presión $(\mathrm{mm})$

De esta manera, la selección de cada tasa de compresión, estableciendo un espesor de chapa nominal de $1.8 \mathrm{~mm}$ (espesor de chapa promedio latifoliadas, INFODEMA S.A.), otorgó las siguientes distancias entre cuchillo y barra de presión (Tabla 1). 
Tabla 1. Espesores de chapa nominal y real de Eucalyptus nitens para las tres tasas de compresión usadas en el torno de debobinado "Cremona".

\begin{tabular}{|c|c|c|c|c|}
\cline { 2 - 5 } \multicolumn{1}{c|}{} & $\begin{array}{c}\text { Tasa de } \\
\text { Compresión }\end{array}$ & $\begin{array}{c}\text { Espesor de Chapa } \\
\text { Nominal }\end{array}$ & $\begin{array}{c}\text { Espesor Real de } \\
\text { Chapa }\end{array}$ & $\begin{array}{c}\text { Distancia entre cuchillo } \\
\text { y barra de presión }\end{array}$ \\
\cline { 2 - 5 } & $\%$ & $\mathrm{~mm}$ & $\mathrm{~mm}$ & $\mathrm{~mm}$ \\
\hline TC1 & 0.5 & 1.8 & 1.88 & 1.87 \\
\hline TC2 & 3.5 & 1.8 & 1.85 & 1.79 \\
\hline TC3 & 5.0 & 1.8 & 1.82 & 1.73 \\
\hline
\end{tabular}

\section{Fabricación chapas:}

El proceso de fabricación de chapas y tableros se realizó en la planta de tableros INFODEMA S.A. en Valdivia región de los Ríos. Las condiciones de proceso utilizadas en planta fueron las siguientes:

- Descortezado: manual

- Macerado en piletas: $10 \mathrm{~h}$ a $80^{\circ} \mathrm{C}$.

- Debobinado:

- Angulo del cuchillo $21^{\circ}$

- Angulo de incidencia $0^{\circ}$

- Velocidad de rotación $60 \mathrm{~m} / \mathrm{s}$

- Secador de malla a $190{ }^{\circ} \mathrm{C}$ y $2.1 \mathrm{~m} / \mathrm{s}$ de velocidad.

- Por cada tasa de compresión utilizada en el proceso se realizó el seguimiento en línea de las chapas hasta el secado de ésta.

Las chapas obtenidas fueron dimensionadas e identificadas en función de cada tasa de compresión y se controló el espesor y la calidad visual de la chapa, descartando aquellas con exceso de rajaduras y agrietamiento. Estas rajaduras se produjeron en los extremos de las trozas de Eucalyptus nitens al liberar las tensiones de crecimiento y se prolongaron hacia las chapas. Después del secado se monitoreó la temperatura y el contenido de humedad de las chapas, según normativas de planta.

\section{Análisis de morfología y frecuencia de grietas}

Un cortador laser marca LASERJET 2500 se utilizó para cortar las chapas y obtener probetas rectangulares de $3 \times 20 \mathrm{~cm}$, con el fin de observar las grietas de debobinado en el espesor. Para cada tasa de compresión se fabricaron 20 probetas de estas chapas, obtenidas aleatoriamente. Mediante el uso de una herramienta de fabricación propia en forma de semi-circunferencia (Figura 4), de radio $15 \mathrm{~cm}$, se observaron las grietas de debobinado; se utilizó dicho radio de curvatura para evitar daño adicional en la chapa producto del montaje en este dispositivo. 


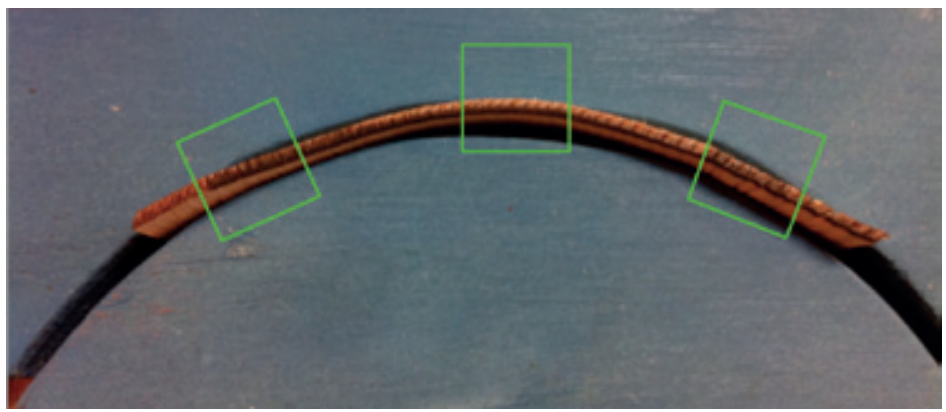

Figura 4. Dispositivo en forma de semi-circunferencia para la observación de grietas de debobinado en las probetas de chapas.

\section{Evaluación de la morfología y frecuencia de grietas:}

a) Captura de Imágenes:

Las imágenes fueron capturadas usando un estéreo microscopio NIKON SMZ1000, equipado con cámara digital Micro Publisher 3.3 RTV y software de captura de imágenes QCapture Suite. Se obtuvieron 3 fotografías del centro y extremos por cada probeta de chapa (Figura 4). En la captura de imágenes se utilizó una magnificación de 10x. En las imágenes capturadas se midió: frecuencia, largo y área de la grietas.

b) Análisis de Imágenes:

Utilizando el software de análisis de imágenes Image Pro Plus 6.2, se realizo las mediciones antes mencionadas. Usando una regla micrométrica de $1 \mathrm{~mm}$, se calibró el software para las mediciones de longitud $(\mathrm{mm})$ y área $\left(\mathrm{mm}^{2}\right)$ de las grietas en estudio.

\section{c) Largo de grietas:}

El largo de cada una de las grietas fue medido en toda la longitud de muestreo (Figura 5), para cada fotografía $(8.58 \mathrm{~mm})$. Se diseñó una metodología de medición, que consistió en dividir la grieta en dos tramos (Tramo A y B), tramos conectados que dan la morfología característica de las grietas de debobinado (Figura 6). El tramo A corresponde a la cara suelta de la chapa, que es donde se produce el corte con el cuchillo debobinador. El largo total de la grieta es la sumatoria del tramo A y B.

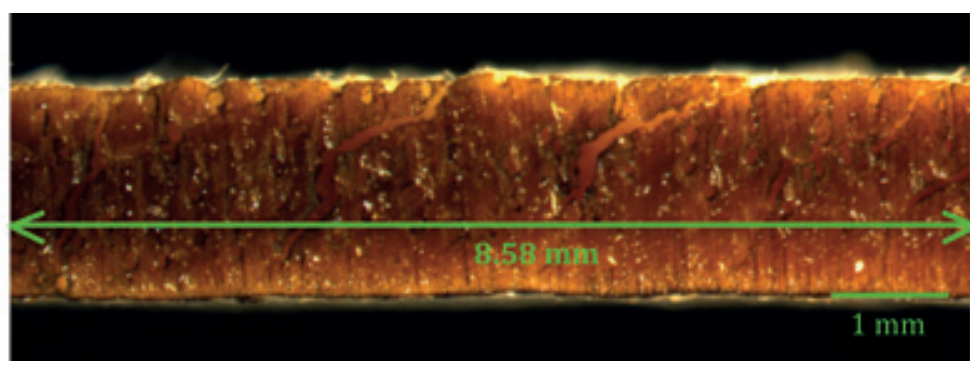

Figura 5. Longitud de muestreo y medición de grietas de debobinado. 
d) Área de grietas:

Usando el software de análisis de imágenes, se midió el área de cada una de las grietas que aparecen en la imagen (Figura 10 y 11); la sumatoria total del área de grietas es evaluada posteriormente.

e) Frecuencia de grietas:

En el largo de la sección de chapa analizada, para cada fotografía es de 2044 píxeles, que corresponden a $8.58 \mathrm{~mm}$ (Figura 5).Contando la cantidad de grietas en el largo observado. Dependiendo de la posición de la grieta, puede considerarse la mitad de una grieta que se observe al final de la fotografía.

\section{Análisis estadístico}

Un Análisis de Varianza (ANOVA) fue llevado a cabo mediante el software STATISTICA 8.0 para el análisis de los resultados. Se utilizaron graficas de barras considerando un intervalo de confianza al 95\% para evaluar la dispersión de los datos y comparar las diferencias significativas.

\section{RESULTADOS Y DISCUSIONES}

La morfología de las grietas en las chapas es dependiente de la tasa de compresión empleada. El análisis de imágenes en la medición de largo de grietas, se distinguió que existe una disminución en el largo de estas a medida que se aumenta la tasa de compresión, existiendo un acortamiento en los dos tramos de medición, pero especialmente en el tramo A (Figura 6). Esta disminución de largo tiende a formar una grieta lineal en chapas obtenidas mediante la tasa de compresión de 5\% (Figura $8-b)$.

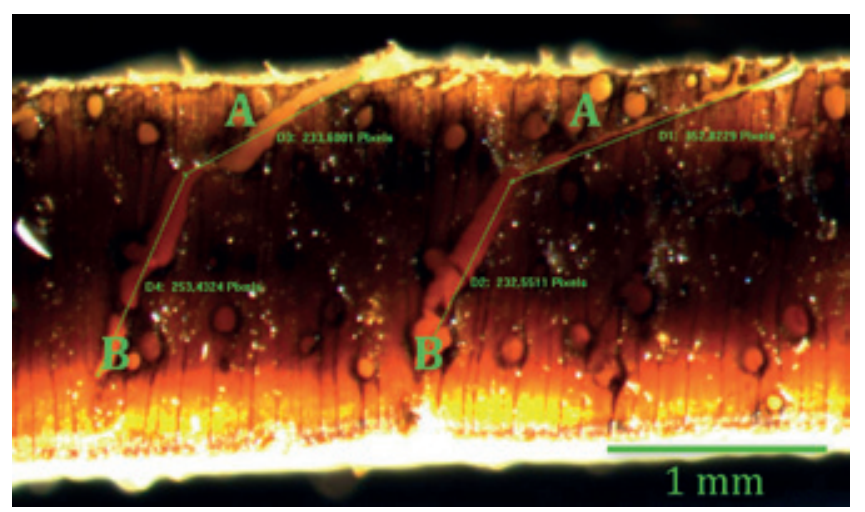

Figura 6. Medición largo Grietas de debobinado en dos tramos (magnificación 10x).

La figura 7 muestra el largo promedio de las grietas de debobinado con un intervalo de confianza al 95\%. El largo de grietas tendió a disminuir a medida que se aumentó la tasa de compresión. El largo promedio de las grietas de debobinado fue de $1.79,1.70$ y $1.53 \mathrm{~mm}$, para las tasas de compresión TC1, TC2 y TC3, respectivamente. 


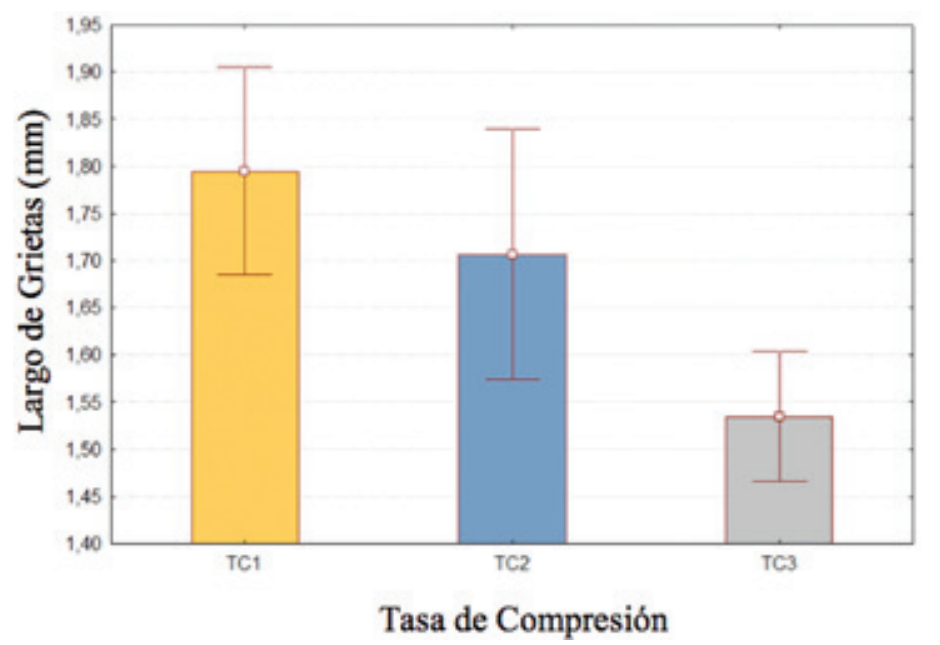

Figura 7. Comparación de tres tasas de compresión con respecto al largo de grietas ( $\mathrm{mm})$, considerando un intervalo de confianza del 95\%.

Las chapas con una tasa de compresión $0.5 \%$ presentaron mayor cantidad de grietas, con una morfología en dos segmentos-orientaciones (Figura 8-a). En comparación a las chapas sometidas a una tasa de compresión de 5\%, se observó mayor número de grietas lineales (Figura 8-b), es decir, a mayor TC el largo de grietas disminuye.

a)

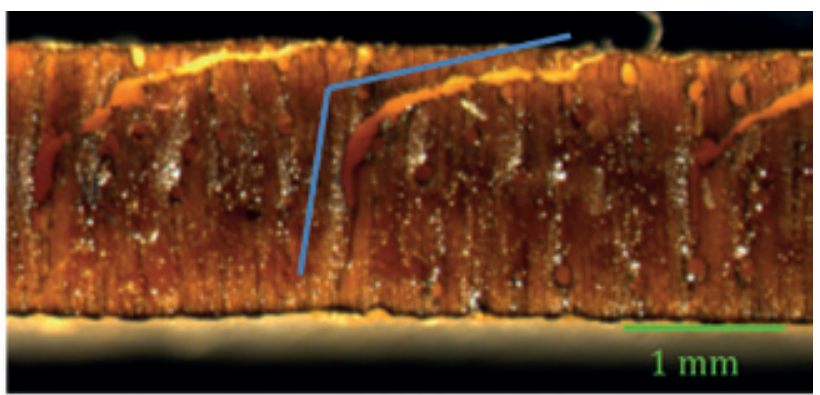

b)

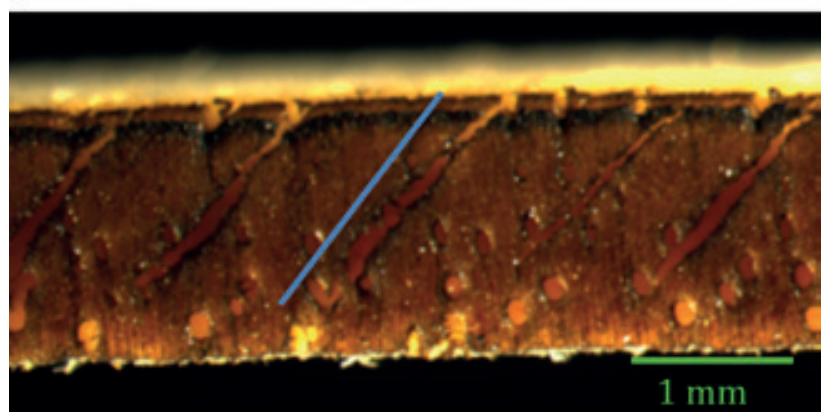

Figura 8. Tipo de grietas observadas

a) grietas en dos tramos.

b) grietas lineales.

La figura 9, muestra el área de las grietas de debobinado con respecto a la tasa de compresión utilizada. Tal y como se observa, el área de las grietas tendió a disminuir a medida que aumentó la 
tasa de compresión. Los resultados para el área promedio de grieta de debobinado fueron TC1 con $1.076 \mathrm{~mm}^{2}$, TC2 con $0.887 \mathrm{~mm}^{2}$ y TC3 con $0.671 \mathrm{~mm}^{2}$.

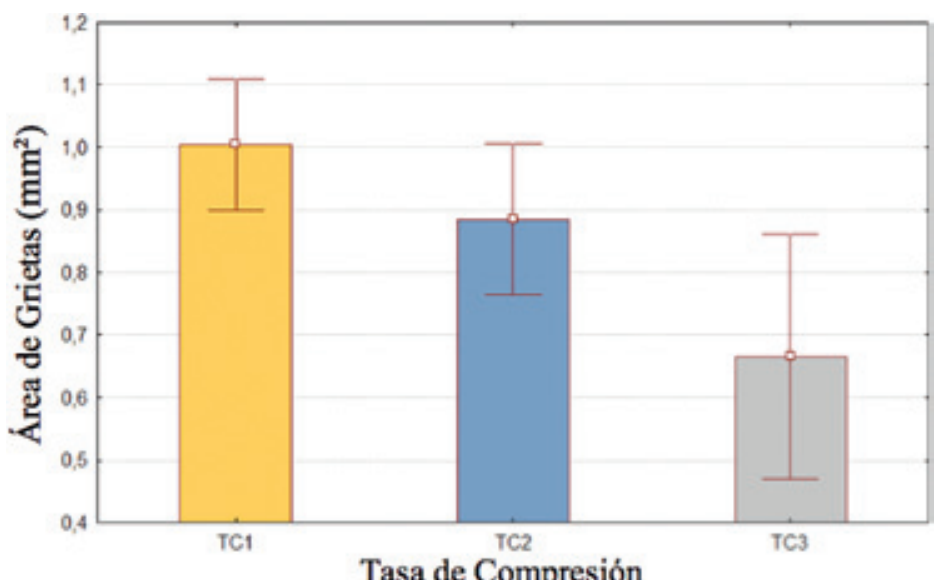

Figura 9. Comparación del área de grietas $\left(\mathrm{mm}^{2}\right)$ en la longitud de chapa de interés analizada $(8.58 \mathrm{~mm})$ para las tres tasas de compresión, considerando un intervalo de confianza del $95 \%$.

A una tasa de compresión de $0.5 \%$, las grietas fueron abiertas (Figura 10), a diferencia de la tasa de compresión de 5\%, la cual generó grietas más cerradas (Figura 11); ya que se obtuvo una chapa con fibras menos apretadas, las que tienden a perder menos agua por compresión provocada por la barra de presión en el torno de debobinado, situación que podría deberse a la mayor cantidad de evaporación de agua durante el secado de la chapa, existiendo posiblemente una pérdida de agua más violenta y expandiendo el área de grietas en chapas obtenidas con tasas de compresión menores. También se observó que existen grietas más abiertas cuando aumentó cantidad de vasos en el espesor de la chapa. Tal como lo discutió Gacitúa et al. (2007), los vasos son elementos que concentran esfuerzos alrededor de ellos, generando colapso de células y microgrietas.

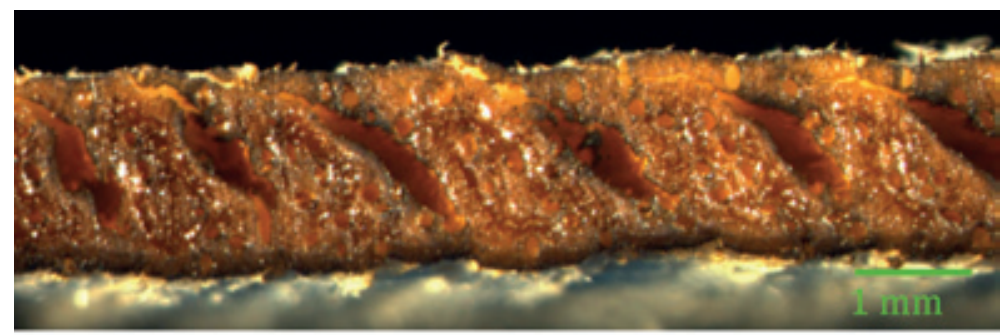

a)

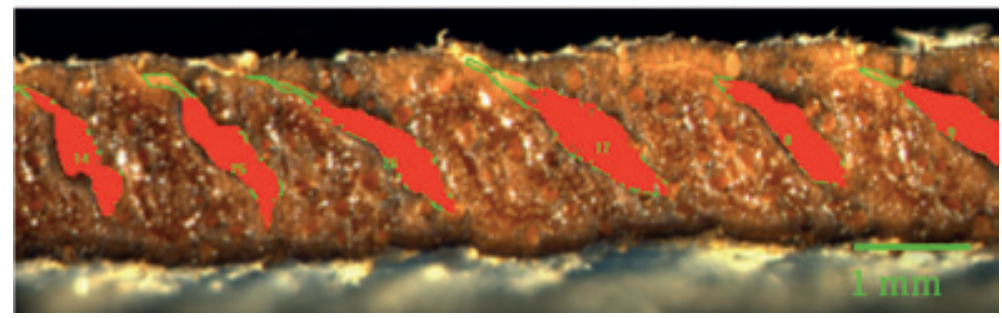

b)

Figura 10. a) Grietas en el espesor de chapas de Eucalyptus nitens (ej. grieta abierta) b) tratamiento de las imágenes con Image Pro plus para la medición área Grietas de debobinado. 


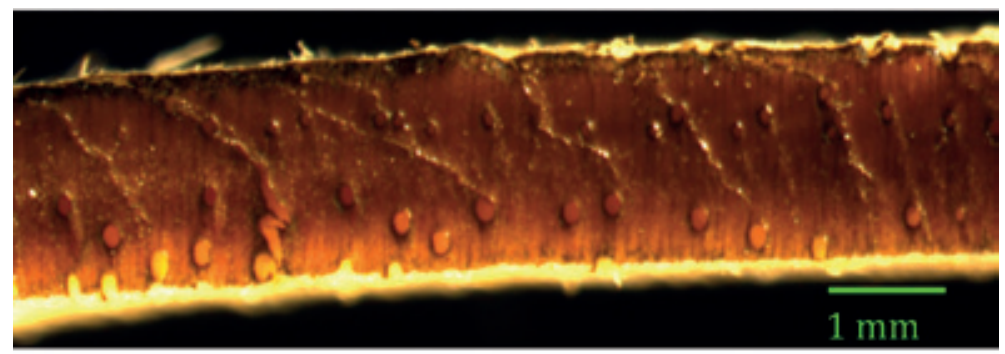

a)

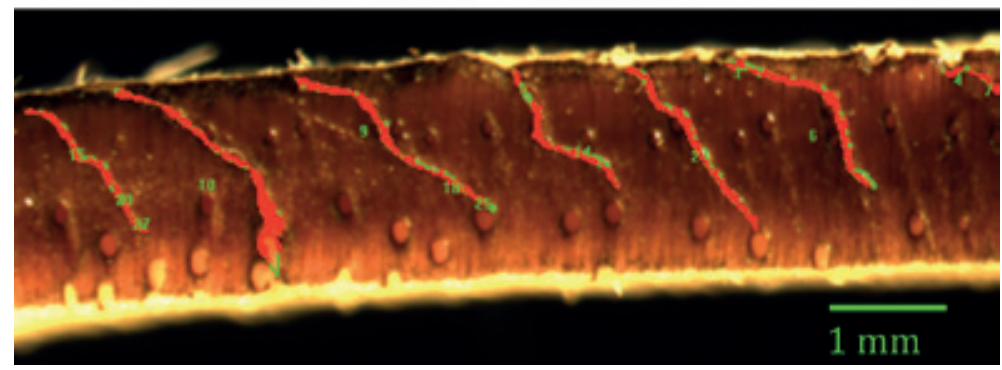

b)

Figura 11. a) Grietas en el espesor de chapas de Eucalyptus nitens (ej. grieta cerrada).

b) tratamiento de las imágenes con Image Pro Plus para la medición área grietas de debobinado.

El análisis de frecuencia de grietas de debobinado medida en un segmento de chapa de $8.58 \mathrm{~mm}$ de longitud (Figura 12), mostró una tendencia al aumento del número de grietas entre TC1 con 4.89 grietas y TC2 con 4.96 grietas, no existiendo diferencia significativa entre estas frecuencias según el ANOVA $(p>0.05)$ y tampoco respecto al número de grietas de TC3 con 5.77 grietas (Figura 13).

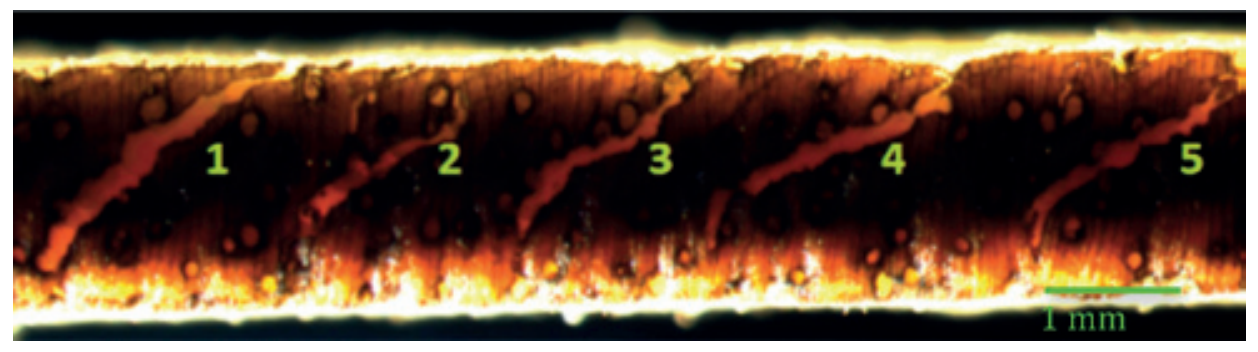

Figura 12. Medición número grietas de debobinado en el largo de chapa de $8.56 \mathrm{~mm}$. 


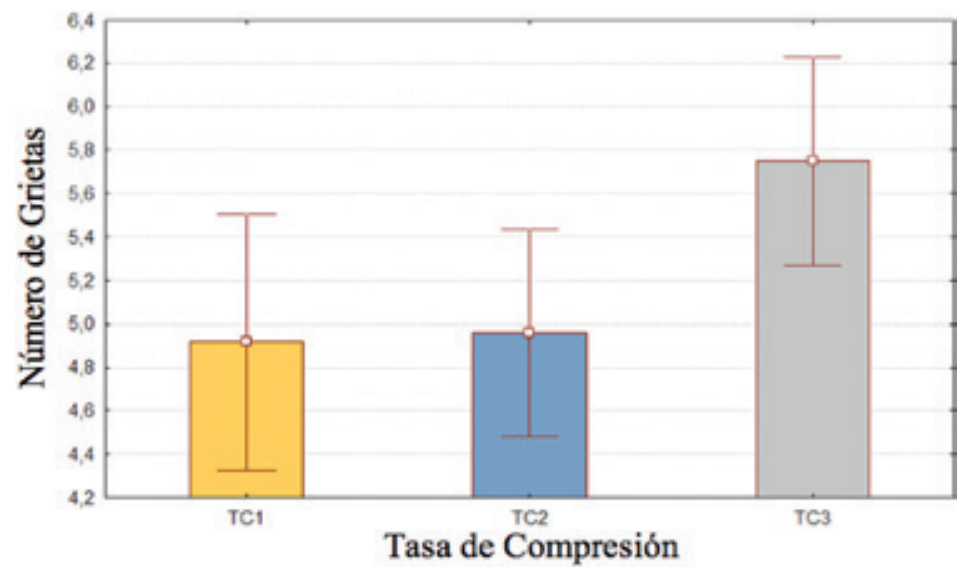

Figura 13. Número de grietas por cada $8.58 \mathrm{~mm}$, para tres tasas de compresión, considerando un intervalo de confianza del $95 \%$.

Por consiguiente, el análisis morfológico de las grietas producidas en el proceso de debobinado, mostró que existe una tendencia a disminuir el largo en los tramos A y B, además de haber mayor número de grietas lineales y cortas, a medida que se aumenta la tasa de compresión. Al aumentar la tasa de compresión se obtiene una chapa más apretada, y la fractura del material o propagación de la grieta no se completa a través del espesor de la chapa, al obtener menores valores en área y dimensiones de grietas de debobinado para tasas de compresión mayores, las chapas son más rígidas y de mejor calidad visual.

Según resultados de estudios anteriores sobre tasas de compresión y temperaturas de macerado en pino oregón (Pseudotsuga menziesii) y ciprés lusitánico (Cupressus lusitanica) (Devlieger et al. 1986), con tasas de compresión altas (entre 12\% y 16\%) y temperaturas de macerado superiores a 70 ${ }^{\circ} \mathrm{C}$, el agrietamiento en chapas disminuye y mejoran las propiedades mecánicas en ellas.

En análisis morfológico para este estudio de tasa de compresión, no existe una diferencia significativa entre la TC1 - TC2 y tampoco entre TC2 - TC3 (ANOVA, $p>0.05$ ), pero si entre la TC1 y TC3 (ANOVA, $p<0.05$ ). Por lo que para posteriores pruebas, se recomienda aumentar la tasa de compresión para evaluar la morfología de grietas de debobinado, ampliando el rango entre las tasas de compresión estudiadas.

En el proceso de debobinado, existe un daño mecánico por compresión, producido por el efecto del roce de la barra de presión, que no es significativo para latifoliadas (Lutz 1978), respecto a la apariencia superficial de la chapa en lo que se refiere a rugosidad, rajadura y ondulación. No obstante la rajadura en los cantos de la chapa no se pudo minimizar debido a que las trozas de Eucalyptus nitens poseían partiduras en los extremos, defecto representativo de esta especie por la liberación de tensiones de crecimiento (Ananías et al. 2009, Caniza et al. 2007, Smith et al. 2003, Touza 2001).

Este defecto podría minimizarse utilizando sobre-largos en los trozos hasta la etapa previa al debobinado, donde se podría ajustar el largo del trozo dejando sus caras libres de rajaduras. 


\section{CONCLUSIONES}

De los resultados obtenidos, relacionados con el efecto de la tasa de compresión en la calidad de chapas de Eucalyptus nitens, se puede concluir que para obtener chapas de esta especie con menor largo y área de grietas de debobinado, una de las modificaciones factibles de aplicar en proceso es el aumento de la tasa de compresión, es decir, ajustar a menor distancia la barra de presión y el cuchillo debobinador.

En la evaluación de área de grietas se observó que con la tasa de compresión 0.5\% y 3.5\%, las grietas de debobinado estaban más abiertas, es decir, tenían más área respecto a la sección transversal de chapa en estudio.

Respecto de la morfología de grietas, al usar una tasa de compresión menor (bajo apriete) genera mayor cantidad de grietas en forma de "L", medidas en dos tramos de mayor largo. Por el contrario para una chapa obtenida con una tasa de compresión mayor se obtienen grietas más cortas y rectas, eliminando el efecto $\mathrm{L}$ de dos tramos.

Al utilizar una tasa de compresión menor, se encontró una menor frecuencia de grietas pero de mayores dimensiones y área, a diferencia de las chapas obtenidas con una tasa de compresión mayor que según estos resultados tienen una mayor frecuencia de grietas, pero de menor dimensión y área, no existiendo grandes zonas de colapso en el material para este tipo de chapa.

Para las condiciones de proceso utilizadas en esta investigación es recomendable la utilización de una tasa de compresión mayor en la obtención de chapas de Eucalyptus nitens para obtener chapas con menor ondulación y menor daño superficial producido por el agrietamiento, siguiendo las condiciones de proceso usadas en esta investigación.

\section{AGRADECIMIENTOS}

Los autores de este documento agradecen al Proyecto Fondef D07i1101 por proveer el equipamiento para desarrollar la investigación, a Forestal Mininco por la donación de la materia prima, a empresa Oxiquim S.A. por proporcionar resina y a la empresa Infodema por facilitar sus instalaciones donde se desarrollaron las pruebas.

\section{REFERENCIAS}

Ananias, R.; Diaz, C.; Leandro, L. 2009. Estudio preliminar de la contracción y el colapso en Eucalyptus nitens. Maderas. Ciencia y Tecnología 11(3):251-260.

Caniza, F.; Lopez, J.; Montenegro, P.; Assame, S.; Aparicio, J. 2007. Variación de las tensiones de crecimiento en tres clones de Eucalyptus grandis según el estado de competencia individual. XXII Jornadas Forestales de entre Ríos, Concordia. Octubre de 2007: 1-9.

Denaud, L.; Bleron, L.; Ratle, A.; Marchal, R. 2007. Online control of wood peeling process: Acoustical and vibratory measurements of lathe checks frequency. INRA. EDP Sciences 67: 569-575.

Devallance, D.V.; Funck, J. W.; Reeb, J.E. 2007. Douglas-fir plywood gluebond quality as influenced by veneer roughness, lathe checks, and annual ring characteristics. Forest Products Journal 57(1-2): 21-28. 
Devlieger, F.; Cuevas, H.; Inzunza, L. 1986. Efecto de las variables de debobinado en pino oregón y ciprés lucitánico. Bosque 7(2):115-120.

Lutz, J. 1978. Wood Veneer: Log Selection, Cutting and Drying. Forest Service, US Department of Agriculture. Washington D.C.

Marchal, R.; Mothe, F.; Denaud, L. E.; Thibaut, B.; Bleron, L. 2009. Cutting forces in wood machining- Basics and applications in industrial processes. A review. Holzforschung 62(2):157-167.

Muñoz, F.; Espinosa, M.; Herrera, M.; Cancino, J. 2005. Características del crecimiento en diámetro, altura y volumen de una plantación de Eucalyptus nitens sometida a tratamientos silvícolas de poda y raleo. Bosque 26(1): 93-99.

Palubicki, B.; Marchal, R.; Butaud, J. C.; Denaud, L. E.; Blèron, L.; Collet, R.; Kowaluk, G. 2009. A Method of Lathe Checks Measurement; SMOF device and its software. Eur. J. Wood Prod. 68(2): 151-159.

Smith, I.; Landis, E.; Gong, M. 2003. Fracture and Fatigue in Wood. John Wiley \& Sons Ltd. ISBN 0-471-48708-2, USA.

Touza, M. 2001. Tensiones de crecimiento en Eucalyptus globulus de Galicia (España). Influencia de la selvicultura y estrategias de aserrado. Maderas. Ciencia y Tecnología 3 (1-2): 68-89. 
